Review

\title{
Use of Intense Pulsed Light to Mitigate Meibomian Gland Dysfunction for Dry Eye Disease
}

\author{
Abhishek Suwal ${ }^{1 *}$, Ji-long Hao ${ }^{1^{*}}$, Dan-dan Zhou ${ }^{*}$, Xiu-fen Liu ${ }^{1^{*}}$, Raja Suwal ${ }^{3}$ and Cheng-wei Lu ${ }^{1^{凶}}$ \\ 1. Department of Ophthalmology, The First Hospital of Jilin University, No. 71 of Xinmin St., Changchun, Jilin Province, 130021, China. \\ 2. Department of Radiology, The First Hospital of Jilin University, No. 71 of Xinmin St., Changchun, Jilin Province, 130021, China. \\ 3. Department of Radiology, Koshi Zonal Hospital, Biratnagar, Province No. 1, Nepal. \\ ${ }^{*}$ Co-first authors with equal contributions. \\ $\triangle$ Corresponding author: Cheng-wei Lu, M.D., Ph.D. Department of Ophthalmology, The First Hospital of Jilin University, No. 71 of Xinmin St., Changchun, \\ Jilin Province, 130021, China. E-mail: lcwchina800@sina.com; Telephone No.: +8615904425848. \\ (C) The author(s). This is an open access article distributed under the terms of the Creative Commons Attribution License (https://creativecommons.org/licenses/by/4.0/). \\ See http://ivyspring.com/terms for full terms and conditions.
}

Received: 2020.01.25; Accepted: 2020.05.24; Published: 2020.06.01

\begin{abstract}
Dry Eye Disease (DED) is a common ocular condition that needs prompt diagnosis and careful treatment interventions. If left untreated, it can lead to numerous sight-threatening complications, including ulceration of the cornea, blepharitis, alterations of the tear film, conjunctivitis, and in severe cases, may lead to scarring, thinning, and even perforation of the cornea. Intense pulsed light (IPL) is a non-laser high-intensity light source that has shown to play a valuable role in dry eye disease. Recent evidence from various research works has shown that IPL modifies the mechanism of meibomian gland dysfunction (MGD), which helps to relieve the symptoms of DED. In this review, we demonstrated the mechanism of action of IPL, including its benefits on DED. The emerging evidence shows that the role of IPL in DED is novel and therapeutic. These results direct us to conclude that IPL is a potentially beneficial tool and essential future therapy for dry eye disease. Advances in the treatment of DED will lead to a better quality of life. However, tools to recognize potentially severe side effects of DED earlier in order to treat or prevent them must be developed.
\end{abstract}

Key words: dry eye disease; intense pulsed light; meibomian gland dysfunction; mechanism of action; meibum

\section{Introduction}

An intense pulsed light (IPL) device is a nonlaser high-intensity light source that uses a highperformance flash lamp to produce a non-coherent light output of large wavelength, usually, in the range of 500 to $1200 \mathrm{~nm}$. Light pulses generated by most modern devices are produced by bursts of electrical current passing through a xenon gas-filled chamber [1]. IPL use in the medical field relies on the basis that specific targets for energy absorption (chromophores) are capable of absorbing energy from this broad spectrum of light wavelength (absorptive band) without exclusively being targeted by their maximum absorption peak. The working principle of the IPL is based on selective photo thermolysis, in which thermally mediated radiation damage is limited to have chosen epidermal and dermal pigmented targets at the cellular or tissue structural levels [2]. The initial published report of the use of an IPL device in ophthalmology dates back to 2002 when Toyos et al. observed improvements in MGD related Dry Eye Disease (DED) patients [3,4].

DED is a common ocular condition that needs prompt diagnosis and careful treatment interventions. If left untreated, it can lead to numerous sightthreatening complications, including ulceration of the cornea, blepharitis, alterations of the tear film, conjunctivitis, and in severe cases, significant drying of the eye may lead to scarring, thinning, and even perforation of the cornea [5]. Henceforth, early diagnosis and proper treatment are necessary to prevent further complications and to restore the vision as well as maintaining the integrity of eyelids. The cause of dry eye varies from obstructive such as age-related disorder to evaporative such as meibomian gland dysfunction (MGD) [6].

IPL uses electromagnetic waves of desired 
wavelengths to dilate the capillaries, causing them to involute [7]. This results in the suppression of the leaked inflammatory mediators, which interrupts the vicious cycle of inflammation and improving symptoms of dry eye. It also works with the help of thermal pulsation for many patients [8]. In the incidence of chronic inflammation, the meibum's composition changes to include more monounsaturated fats. Those fats have a significantly higher melting point of close to $45{ }^{\circ} \mathrm{C}$ - warmer than body temperature [9]. This meibum does not melt into the tear film's lipid layer as it should, and it clogs the glands. Thermal pulsation therapy combines sustained heat and pressure to liquefy the meibum and clear the glands. Manually expressing glands is less effective, uncomfortable for patients, and potentially scarring [10]. Thermal pulsation is gentle and effective. With these mechanisms, we have come to an understanding that IPL helps to relieve the symptoms of dry eye [11]. This literature review aims to compare a good deal of research work done in the field of IPL and their associated results in treating DED (Table 1).

\section{Mechanisms of action}

\section{Thrombosis of abnormal blood vessels}

The energy produced by IPL, directed towards the eyelid, is absorbed by hemoglobin and is transformed into heat and causes the localized destruction of superficial blood vessels [12]. Obliteration of atypical erythematous blood vessels reduces a significant reservoir of inflammatory mediators, thus removing a significant source of inflammation from the eyelids and meibomian glands [13].

Table 1. Summary of studies on IPL for DED Therapy

\begin{tabular}{|c|c|c|c|c|c|c|c|}
\hline Year & Design & Patients (n) & IPL sessions (n) & Dry eye symptom & BUT & Meibomian function & Reference \\
\hline 2020 & $\begin{array}{l}\text { Prospective randomised } \\
\text { double-masked placebo-controlled }\end{array}$ & 58 & 5 & $\begin{array}{l}\text { Improved OSDI, SPEED, } \\
\text { SANDE }\end{array}$ & Improved & Improved & {$[41]$} \\
\hline 2020 & $\begin{array}{l}\text { Prospective randomized } \\
\text { double-masked sham-controlled }\end{array}$ & 114 & 3 & Improved OSDI & Improved & Improved & {$[62]$} \\
\hline 2020 & $\begin{array}{l}\text { Prospective controlled } \\
\text { randomized }\end{array}$ & 29 & 3 & Improved OSDI & Improved & Improved & {$[32]$} \\
\hline 2020 & Retrospective & 43 & $\begin{array}{l}\text { Mild group: 2; } \\
\text { Moderate } \\
\text { group: } 3 ; \\
\text { Severe group: } 4\end{array}$ & $\begin{array}{l}\text { Improved OSDI in mild } \\
\text { and moderate atrophy } \\
\text { patients, not severe ones }\end{array}$ & $\begin{array}{l}\text { Improved in mild } \\
\text { and moderate } \\
\text { atrophy patients, not } \\
\text { in severe ones }\end{array}$ & $\begin{array}{l}\text { Improved in mild and moderate } \\
\text { atrophy patients, not in severe ones }\end{array}$ & [45] \\
\hline 2019 & $\begin{array}{l}\text { Prospective controlled } \\
\text { randomized }\end{array}$ & 45 & 3 & Improved SPEED & Improved & Improved & {$[60]$} \\
\hline 2019 & $\begin{array}{l}\text { Prospective controlled } \\
\text { randomized }\end{array}$ & 45 & 8 & Improved SPEED & Improved & Improved & [43] \\
\hline 2019 & Prospective controlled & 12 & 1 & Improved OSDI & Improved & - & {$[66]$} \\
\hline 2019 & Prospective comparative & 40 & 3 & Improved OSDI & Improved & - & [63] \\
\hline 2019 & Prospective noncomparative & 30 & 3 & Improved OSDI & Improved & Improved & [56] \\
\hline 2019 & Prospective noncomparative & 19 & 3 & $\begin{array}{l}\text { Subjective symptoms } \\
\text { improved }\end{array}$ & Improved & No statistically significant changed & [48] \\
\hline 2019 & Prospective noncomparative & 30 & 3 & Improved OSDI & Improved & Improved & [76] \\
\hline 2019 & Case-control & 82 & 1 & Improved OSDI & Improved & Improved & [70] \\
\hline 2019 & Retrospective & 28 & 3 & $\begin{array}{l}\text { Subjective symptoms } \\
\text { improved }\end{array}$ & Improved & Improved & [49] \\
\hline 2019 & Retrospective & 25 & - & Improved OSDI & Improved & Improved & [22] \\
\hline 2018 & $\begin{array}{l}\text { Prospective, randomized, } \\
\text { double-masked, controlled }\end{array}$ & 44 & 3 & Improved SPEED & Improved & Improved & [59] \\
\hline 2018 & Prospective controlled randomized & 28 & 3 & Improved SPEED & Improved & Improved & [57] \\
\hline 2018 & Prospective noncomparative & 31 & $4-8$ & Improved SPEED & Improved & Improved & [44] \\
\hline 2018 & Prospective noncomparative & 26 & 3 & $\begin{array}{l}\text { Subjective symptoms } \\
\text { improved }\end{array}$ & Improved & - & [68] \\
\hline 2018 & $\begin{array}{l}\text { Prospective noncomparative } \\
\text { non-randomized }\end{array}$ & 17 & 4 & Improved OSDI & Improved & Improved & [69] \\
\hline 2018 & Prospective Cohort & 35 & 3 & Improved OSDI & Improved & Improved & [72] \\
\hline 2017 & $\begin{array}{l}\text { Prospective, randomized, } \\
\text { double-masked, controlled }\end{array}$ & 44 & 3 & Improved OSDI, SPEED & Improved & Improved & [67] \\
\hline 2017 & $\begin{array}{l}\text { Prospective, randomized, } \\
\text { double-masked, controlled }\end{array}$ & 44 & 3 & $\begin{array}{l}\text { Improved SPEED with no } \\
\text { statistical difference }\end{array}$ & Improved & Improved & [74] \\
\hline 2017 & $\begin{array}{l}\text { Prospective interventional } \\
\text { noncomparative }\end{array}$ & 40 & 4 & Improved SPEED & Improved & Improved & [50] \\
\hline 2017 & Prospective noncomparative & 36 & 4 & - & Improved & - & {$[47]$} \\
\hline 2016 & Prospective, open label & 40 & 4 & $\begin{array}{l}\text { Subjective symptoms } \\
\text { improved }\end{array}$ & Improved & Improved & [75] \\
\hline 2016 & Retrospective & 100 & 4 & Improved OSDI & Improved & Improved & {$[61]$} \\
\hline 2015 & Prospective controlled & 28 & 3 & Improved OSDI, SPEED & Improved & - & [37] \\
\hline 2015 & $\begin{array}{l}\text { Retrospective noncomparative } \\
\text { case series }\end{array}$ & 91 & 7 & $\begin{array}{l}\text { Subjective symptoms } \\
\text { improved }\end{array}$ & Improved & - & [3] \\
\hline
\end{tabular}




\section{Eradication of Demodex and reducing the bacterial load}

Demodex is an ectoparasite that usually burrows deep into sebaceous and meibomian glands to feed on the meibum secretions [14-16]. A direct consequence of the spread of Demodex is the dramatic increase in bacterial load on the eyelids [17], particularly Bacillus oleronius [18]. The pigmented exoskeleton of Demodex comprises a chromophore that absorbs IPL energy [19]. Histology analysis confirmed that IPL treatment induces coagulation and necrosis of Demodex [20]. By eradication of Demodex, IPL could help decrease the microbial load on eyelids and possibly break the malicious cycle of inflammation. Thus, the annihilation of Demodex and reducing the bacterial load on the eyelids [19-21] is the most significant approach towards reducing the incidence of MGD in DED patients [22].

\section{Photobiomodulation}

Photobiomodulation is a procedure by which light in the visible and infrared portions of the electromagnetic spectrum induces intracellular changes at the gene and protein levels [23]. IPL produces a photochemical cascade, inducing changes in the redox properties of components along the mitochondrial respiratory chain, leading to faster electron transfer and, hence, to an increase in adenosine triphosphate production [24]. In the case of fibroblasts, cell proliferation is boosted, and collagen synthesis is increased [25]; skin-homing $\mathrm{T}$ cells are recruited [26]; local blood flow is increased; macrophages cells are activated [27]; epidermal keratinocytes increase the secretion of proinflammatory or anti-inflammatory cytokines and chemokines (Figure 1). The ability of IPL to activate fibroblasts and enhance collagen synthesis is the basis for the efficacy of skin rejuvenation as well as MGD related DED treatment $[28,29]$. At the eyelid skin level, this effect could contrast the natural tendency of the skin to lose rigidity and elasticity with aging. This process could lead to poor apposition of the lid margins and incomplete blinks, resulting in reduced meibum secretion and increased tear evaporation.

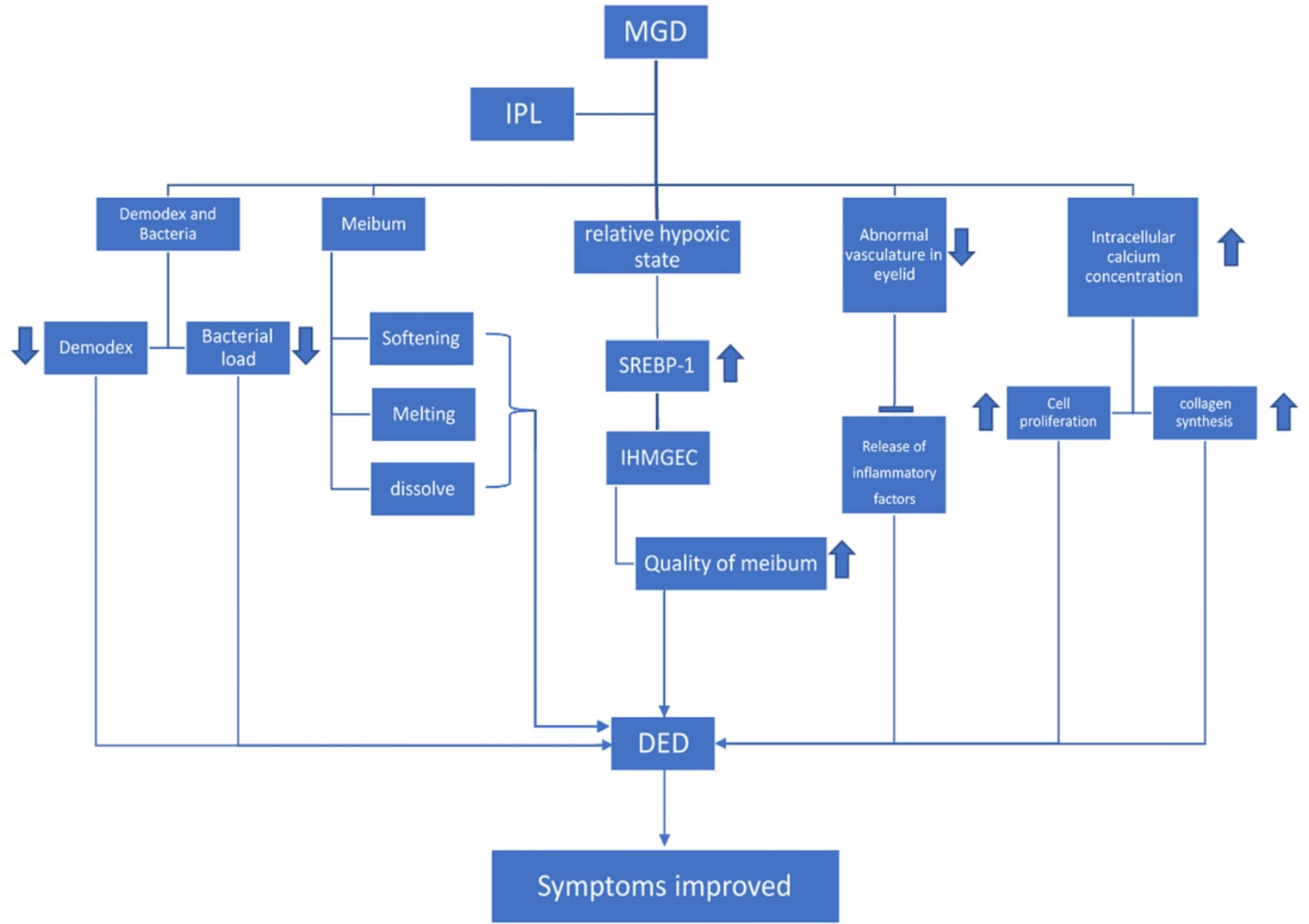

Figure 1. MGD, when treated with IPL, helps reduce the Demodex as well as bacterial load. Whereas in the meibomian gland, IPL helps to soften, melt, and dissolve the meibum. IPL helps create a relative hypoxic state in the MG, which stimulates the expression of SREBP-1 in differentiating IHMGECs, thereby improving the quality of lipid content in meibum. IPL also helps to reduce the abnormal vasculature in the eyelid, thus inhibiting the release of inflammatory factors. Intracellular calcium concentration is increased, which leads to an increase in cell proliferation and collagen synthesis. These mechanisms help in relieving the symptoms of DED. 


\section{Effects on meibum}

The temperature of the eyelid significantly regulates the flow of meibum secretion. IPL induces heating of the meibomian glands and dissolving the meibum, activation of fibroblasts, and enhancing the synthesis of new collagen fibers, thrombosis of damaged blood vessels [12] below the skin surrounding the eyes. Bäumler et al. suggested that in medium and large blood vessels $(>150 \mu \mathrm{m})$, a single IPL pulse of $30 \mathrm{~ms}$ duration raises the temperature at the center of the vessel to $80{ }^{\circ} \mathrm{C}-90{ }^{\circ} \mathrm{C}$, above the temperature required to cause coagulation and thrombosis. In contrast, in small $(60 \mu \mathrm{m})$ blood vessels, the temperature may reach only $45^{\circ} \mathrm{C}-70^{\circ} \mathrm{C}$, depending on the flow [30]. This rise in temperature is insufficient to destroy blood vessels. However, it is probably enough to raise the temperature of eyelid skin (and meibomian glands) by a few degrees, perhaps above the phase-transition temperature. Even if brief, this thermal response could be enough to unclog the meibomian glands and reinstate their ability to excrete meibum during blinking [31]. According to the different IPL patterns, "Optimal Pulse Technology" (OPT) was more effective in improving meibomian glands function in lower eyelids and partial tear film signs than "Intense Regulated Pulsed Light" (IRPL) IPL treatment [32].

\section{Effects on pro- and anti-inflammatory molecules and suppression of MMPs}

Factors that adversely affect tear film stability and osmolarity can induce ocular damage and initiate an inflammatory cascade that generates a robust immunological response, which in turn, may cause further damage at the ocular surface, creating a selfperpetuating inflammatory cycle [33]. IPL has the potential to hinder the inflammatory cycle, by upregulation of anti-inflammatory cytokines, or downregulation of proinflammatory cytokines, or both. The inflammatory cascade in dry eye is extremely complex and incompletely understood. However, it is plausible that at least part of the beneficial effect of IPL on DED patients occurs by interfering with the positive feedback loop underlying the inflammatory cycle of this pathology [31].

Intrusion with the inflammatory cycle by regulation of anti-inflammatory agents and MMPs, diminishing the turnover of skin epithelial cells and reducing the risk of physical obstruction of the meibomian glands, and changes in the levels of Reactive oxidative species helps in preventing the symptoms of dry eye [34].

While any one of these mechanisms of action has likely to explain the effect of IPL on DED, it is also possible that multiple mechanisms of action play various roles. As IPL becomes more frequently used in the treatment of DED, the specific involvement of each of these modes of work will be further elucidated.

\section{IPL induces hypoxic condition on meibomian gland}

Loss of relative hypoxic state of the meibomian gland plays a significant role in the pathogenesis of MGD. Acinar atrophy in a human MGD is linked with a thickening of the basement membrane. This anatomical development may be used to describe a compensatory response to decrease $\mathrm{O} 2$ delivery from adjacent vessels and to restore the relative hypoxia needed for optimal MG function [35]. The latest research by Yiu et al. has demonstrated that human meibomian glands exist in a relatively hypoxic condition, and any alteration in this state dramatically affects the condition of the meibomian gland [36]. As we can assume that heat emitted by IPL creates a hypoxic surrounding in the meibomian gland, IPL may be very beneficial for treating DED through this mechanism. Hypoxia does not influence immortalized human MG epithelial cells (IHMGEC) numbers in basal or proliferating culture conditions but does stimulate the expression of SREBP-1 in differentiating IHMGECs. Hypoxia also significantly increases DNase II activity and IHMGEC terminal differentiation. IPL is known to reduce telangiectases significantly [11], and the closure of these excessive vessels may help the MG to restore its hypoxic environment and normal function [37]. Thus, hypoxia may also play a role in the reported effectiveness of Intense Pulsed Light (IPL) for MGD treatment.

\section{Effects on mucin and corneal nerve}

Mucins are large molecular glycoproteins formed by abundant sugar chains linked to a core protein called apomucin, with $50 \%$ to $80 \%$ of their mass comprised of carbohydrates [38]. Mucin has several essential roles on the ocular surface such as maintenance of lacrimal fluid, lubrication of the ocular surface to ease smooth blinking, formation of a smooth spherical surface for good vision, facility of a barrier for the ocular surface, and trapping and removing pathogens and debris $[39,40]$. The tear film has two distinct layers inside which the aqueous layer contains secreted mucin MUC5AC dispersed within it [40]. Xue et al. found that there were no changes in the MU5AC expression using Conjunctival impression cytology after IPL treatments [41]. Study done in the nerve fibre density and dendritic cell density of the corneal sub-basal layer also showed no change achieved by IPL treatment [41]. Even though the 
changes were not statistically significant, we think that further studies with more extended treatment periods and bigger data are needed.

\section{IPL associated benefits}

\section{Intense pulsed light in patients with refractory meibomian gland dysfunction}

More and more evidence suggested that intense pulsed light when used to treat MGD patients helps to relieve the symptoms of dry eye disease $[11,42-46,47,48-55]$. Arita et al.'s study was to assess the safety and efficacy of intense pulsed light (IPL) joint with meibomian gland expression (MGX) for the treatment of refractory meibomian gland dysfunction (MGD). Her result suggested that the combination of IPL and MGX enhanced homeostasis of the tear film and ameliorated ocular symptoms in patients with a refractory MGD and is thus a promising modality for the treatment of this condition $[43,44]$. IPL treatment improved meibomian gland function, stabilized the tear film, and decreased ocular surface inflammation. Meibum quality, lid margin abnormality, meibum expressibility, tear film breakup time (TBUT), ocular surface staining, and the Ocular Surface Disease Index (OSDI) drastically improved whereas poor meibum expressibility and short TBUT were associated with more significant improvement in the OSDI after IPL [56,57].

IPL treatment, along with meibomian gland probing, showed positive results in treating patients with refractory obstructive meibomian gland dysfunction $[58,59]$. Studies done by Huang et al. on refractory obstructive MGD found out that compared with IPL or MGP alone, the combination MGP-IPL produced the best results in relieving all signs and symptoms and helping patients attain long-lasting symptom relief [60].

\section{Risk vs. benefit associated with IPL treatment}

A study done by Gupta et al. demonstrated that IPL therapy for evaporative DED is a safe procedure. The positive change in objective clinical examination findings and subjective OSDI scoring data suggest that IPL is a safe and effective treatment for patients with evaporative DED. There was a significant increase in oil flow score and TBUT. No significant variations in intraocular pressure or acuity were noted. There were no cases of adverse ocular effects [61]. No adverse effect after the IPL treatment, along with significant improvement in the symptoms of MGD, was noted in some studies [62]. IPL treatment is further confirmed to be safe and effective in Chinese MGD patients with darker skin types (Fitzpatrick skin types III-IV) [63].
Another study done by Rong et al. demonstrated that intense pulsed light applied directly on eyelids combined with meibomian gland expression helps in treating MGD. The study was to determine the efficacy and safety of intense pulsed light (IPL) that was applied directly to the eyelids, and MGX helped to treat MGD. There were no cases of adverse ocular effects. This result clearly shows that IPL combined with MGX safely and effectively treated MGD [59].

Nevertheless, we have to keep in mind that the beam of light produced can be focused on the specific area which selectively damages specific targets in the area being treated [64] (e.g., capillaries, brown spots or tattoo pigment in the skin) allowing them to be removed altogether or the area to be replaced by new cells-depending on the desired treatment. Effects produced by IPL may sometimes be undesired and cause risks such as burns, blistering, and pain [65]. Severe symptoms may include keloids and skin pigmentation. Thus, the physician should inform the concerned patients for the risk vs. beneficial effects of IPL therapy before moving forward with the treatment.

\section{Effect of intense pulsed light therapy on tear proteins, lipids, and inflammatory marker in meibomian gland dysfunction}

IPL helps to improve the symptoms of DED by regulating the concentrations of total lipids, triglycerides, cholesterol, and phospholipids in the tear. Ahmed et al. noted that significant improvements were observed in tear protein concentrations and molecular weight after IPL therapy. The most pronounced effect was in the molecular weight of tear lysozyme, lactoferrin, and albumin. On thin-layer chromatography, the tears in patients with MGD had significantly lower amounts of anionic phosphatidylethanolamine, phosphatidylinositol, and phosphatidylserine, but amounted zwitterionic neutral phospholipid phosphatidylcholine were normal. These anionic phospholipids showed remarkable recovery after IPL therapy [66]. IPL improved tear protein and lipid content and composition. Various studies have shown a promising effect of decreasing interleukin-6, interleukin-17A, and prostaglandin E2 in tear fluid of DED patients after IPL treatment $[43,56,67]$. In addition, they suggested that the decrease in these inflammatory factors was linked to the beneficial improvement of clinical symptoms and signs $[67,68]$. These reductions on the inflammatory factors were associated with changes in corneal staining scores, which is indicative of improvements in ocular surface epithelial damage [69]. Some studies have shown that changes in IL-6, IL-17A, and IL-1 $\beta$ levels were lowest 
at about one week after IPL, which was sooner than the appearance of clinical outcome peaks at one month [70]. This suggests that changes in tear cytokine levels may be more sensitive indexes than clinical signs to show the effects of IPL (Table 2).

\section{Effect on the meibum of MGD by IPL}

Numerous studies have shown that IPL helps loosen the clogged meibum by thermal pulsation therapy. Godin et al., in his research work, suggested that MGD is a vital contributor to dry eye disease in patients with Sjogren disease and should not be overlooked when considering treatment options. Thermal pulsation helped the meibum to release its clogged ducts. A thermal pulsation is a therapeutic option for patients with Sjogren disease who have MGD and dry eye symptoms [71], which can directly improve the quality of meibum. Another study by yin et al. showed that OSDI, TBUT, meibum quality, MG expressibility, and MG dropout improved after treatment. The MG microstructure indexes, including meibum, the MG acinar longest diameter (ALD), MG acinar unit density (AUD), and the positive rate of inflammatory cells (ICs) around glandular structures, were significantly improved by IPL treatment. These findings suggest that IPL treatment improves the symptom of MGD in DED patients. It also improves the associated ocular-surface indexes, MG function, and MG macrostructure as well as eyelid hygiene.

Furthermore, IPL treatment mainly improves MG microstructure and decreases MG inflammation in MGD patients [58,72]. Studies conducted by Chhadva et al. on the meibum of the MGD patients found out that MGD leads to a change in meibum quality and quantity that leads to evaporative dry eye and ocular surface disruption, causing dry eye symptoms in some individuals [73]. These changes can be controlled by the use of IPL in a systematic way so that the difficulty faced by the patient can be minimized [68].

\section{Significant improvement in the first IPL treatment}

Evaluation of the short-term effect on the first IPL treatment combined with meibomian gland expression showed significant improvement in the symptoms of meibomian gland dysfunction [74]. Considerable improvements were observed in single visits after the initial IPL treatment. Compared to baseline, the signs of the eyelid margin, meibomian gland secretion quality, and expressibility were significantly improved at every visit after treatments. There were no local or systemic adverse effects observed in any patient after IPL treatment [75]. Patients exhibited increased oil flow and tear break-up time with an associated decrease in corneal and conjunctival staining [36,71]. A study done by Gao et al. showed that inflammatory markers such as IL-6 were lower at one week of the treatment than that of one month, showing that the IPL treatment starts showing its effect from the earliest [70].

\section{Conclusion and Future Aspects}

DED is a crucial issue in ophthalmic medicine. It has increased in occurrence with the increasing development of screen-based gazettes such as computer and mobile because of which, the blinking rate of fellow human being decreases. Several other factors, such as dust and pollution, also play a significant role in the epidemiology of DED. This literature review aimed to evaluate the use of IPL in MGD and its associated benefits in DED. The reviewed literature suggests that there is an advantage to the use of IPL on ophthalmic cases such as DED. Reduction in symptoms of DED, as well as MGD in conjunction with an improvement in living conditions has been widely documented throughout the literature. These all lead to the conclusion that the use of IPL shall provide vital effectiveness in the field of DED. These findings highlight the potential of IPL as a novel therapeutic procedure in DED. With the evolving trends in medical science, IPL, with current therapeutic management, could be used as a vital tool for MGD as well as DED. Its role as the therapeutic machine could be explored for the welfare of human beings. Current research supports the use of IPL, as discussed above; however, a continuation of current research with consistent and strengthened methodologies will help to justify its use and application in clinical practice.

Table 2. Summary of Reviewed Articles on the tear film and inflammatory markers

\begin{tabular}{|c|c|c|c|c|c|c|}
\hline Study & Design & Patients (n) & IPL sessions (n) & $\begin{array}{l}\text { Inflammatory marker } \\
\text { (down-regulated) }\end{array}$ & Tear protein and lipid & Tear film \\
\hline $\begin{array}{l}\text { Ahmed et al.,[66] } 2019 \\
\text { J Ophthalmic Vis Res }\end{array}$ & Prospective controlled & 12 & 1 & $\begin{array}{l}\text { Prevent inflammatory } \\
\text { mediator secretion }\end{array}$ & Improved & $\begin{array}{l}\text { Lipid concentration of } \\
\text { tear film improved }\end{array}$ \\
\hline $\begin{array}{l}\text { Arita et al.,[43] } 2019 \\
\text { Ocul Surf }\end{array}$ & $\begin{array}{l}\text { Prospective controlled } \\
\text { randomized }\end{array}$ & 45 & 8 & $\begin{array}{l}\text { IL-6, IL-17A, } \\
\text { prostaglandin E2 }\end{array}$ & Improved & $\begin{array}{l}\text { Improved homeostasis of } \\
\text { the tear film }\end{array}$ \\
\hline $\begin{array}{l}\text { Choi et al.,[56] } 2019 \\
\text { Sci Rep }\end{array}$ & $\begin{array}{l}\text { Prospective } \\
\text { noncomparative }\end{array}$ & 30 & 3 & $\begin{array}{l}\text { IL-4, IL-6, IL-10, } \\
\text { IL-17A, and TNF- } \alpha\end{array}$ & Improved & $\begin{array}{l}\text { Tear film break-up } \\
\text { significantly improved } \\
\text { after treatment. }\end{array}$ \\
\hline
\end{tabular}




\begin{tabular}{|c|c|c|c|c|c|c|}
\hline Study & Design & Patients (n) & IPL sessions (n) & $\begin{array}{l}\text { Inflammatory marker } \\
\text { (down-regulated) }\end{array}$ & Tear protein and lipid & Tear film \\
\hline $\begin{array}{l}\text { Liu et al.,[67] } 2017 \\
\text { Am J Ophthalmol }\end{array}$ & $\begin{array}{l}\text { Prospective, randomized, } \\
\text { double-masked, } \\
\text { controlled }\end{array}$ & 44 & 3 & $\begin{array}{l}\text { IL-6, IL-17A, } \\
\text { prostaglandin E2 }\end{array}$ & $\begin{array}{l}\text { The correlation between the } \\
\text { expression of IL-17A, IL-6 in } \\
\text { protein levels showed no } \\
\text { statistically significant }\end{array}$ & $\begin{array}{l}\text { Improved tear film } \\
\text { quality }\end{array}$ \\
\hline $\begin{array}{l}\text { Karaka et al.,[68] } 2018 \\
\text { Eur J Ophthalmol }\end{array}$ & $\begin{array}{l}\text { Prospective } \\
\text { noncomparative }\end{array}$ & 26 & 3 & $\begin{array}{l}\text { IL-6, IL-17A, } \\
\text { prostaglandin E2 }\end{array}$ & Improved & $\begin{array}{l}\text { Significant improvement } \\
\text { in tear film quality }\end{array}$ \\
\hline $\begin{array}{l}\text { Seo et al.,[69] } 2018 \\
\text { Cont Lens Anterior Eye }\end{array}$ & $\begin{array}{l}\text { Prospective } \\
\text { noncomparative } \\
\text { non-randomized }\end{array}$ & 17 & 4 & Down-regulated & Improved & Instability resolved \\
\hline $\begin{array}{l}\text { Gao et al.,[70] } 2019 \\
\text { Int J Ophthalmol }\end{array}$ & Case-control & 82 & 1 & IL-6, IL-17A, and IL-1 $\beta$ & Improved & Improve tear film (TBUT) \\
\hline
\end{tabular}

\section{Abbreviations}

IPL: Intense Pulsed Light; MGD: Meibomian Gland Dysfunction; DED: Dry Dye Disease; MGX: Meibomian Gland Expression; CFS: Conjunctival Fluorescein Staining; TBUT: Tear film Break-up Time; OSDI: Ocular Surface Disease Index; IHMGEC: immortalized human MG epithelial cells; SREBP-1: sterol regulatory element-binding protein 1 .

\section{Acknowledgments}

\section{Funding}

This work was supported by grants by the National Natural Science Foundation of China (Grant No. 81800828) and Achievement Transformation Fund of the first hospital of Jilin University (Grant No.JDYYZH-1902046).

\section{Competing Interests}

The authors have declared that no competing interest exists.

\section{References}

1. Raulin C, Greve B, Grema H. IPL technology: a review. Laser Surg Med. 2003;32(2):78-87.

2. Anderson RR, Parrish JA. Selective photothermolysis: precise microsurgery by selective absorption of pulsed radiation. Science. 1983;220(4596):524-7.

3. Toyos R, McGill W, Briscoe D. Intense pulsed light treatment for dry eye disease due to meibomian gland dysfunction; a 3-year retrospective study. Photomed Laser Surg. 2015;33(1):41-6.

4. Song WJ, Yan XM. [Research progress of intense pulsed light treatment on meibomian gland dysfunction and relevant dry eye diseases]. Zhonghua Yan Ke Za Zhi. 2018;54(2):140-3

5. Lemp MA, Bielory L. Contact lenses and associated anterior segment disorders: dry eye disease, blepharitis, and allergy. Immunol Allergy Clin. 2008;28(1):105-17.

6. Baudouin C, Messmer EM, Aragona P, Geerling G, Akova YA, Benítez-del-Castillo J, et al. Revisiting the vicious circle of dry eye disease: a focus on the pathophysiology of meibomian gland dysfunction. Brit J Ophthalmol. 2016;100(3):300-6.

7. Onesti MG, Fioramonti P. Intense Pulsed Light Systems. International Textbook of Aesthetic Surgery: Springer. 2016;:1123-31.

8. Vegunta S, Patel D, Shen JF. Combination therapy of intense pulsed light therapy and meibomian gland expression (IPL/MGX) can improve dry eye symptoms and meibomian gland function in patients with refractory dry eye: a retrospective analysis. Cornea. 2016;35(3):318-22.

9. Macsai MS. The role of omega-3 dietary supplementation in blepharitis and meibomian gland dysfunction (an AOS thesis). Trans Am Ophthalmol Soc. 2008;106:336-56.

10. Pult H, Nichols JJ. A review of meibography. Optometry Vision Sci. 2012;89(5):E760-E9.

11. Sambhi RS, Sambhi GDS, Mather R, Malvankar-Mehta MS. Intense Pulsed Light Therapy with Meibomian Gland Expression for Dry Eye Disease. Can J Ophthalmol. 2020
12. Papageorgiou P, Clayton W, Norwood S, Chopra S, Rustin M. Treatment of rosacea with intense pulsed light: significant improvement and long-lasting results. Br J Dermatol. 2008;159(3):628-32.

13. Bron AJ, de Paiva CS, Chauhan SK, Bonini S, Gabison EE, Jain S, et al. TFOS DEWS II pathophysiology report. Ocul Surf. 2017;15(3):438-510.

14. Liu J, Sheha H, Tseng SC. Pathogenic role of Demodex mites in blepharitis. Curr Opin Allergy Clin Immunol. 2010;10(5):505-10.

15. Szkaradkiewicz A, Chudzicka-Strugala I, Karpinski TM, Goslinska-Pawlowska O, Tulecka T, Chudzicki W, et al. Bacillus oleronius and Demodex mite infestation in patients with chronic blepharitis. Clin Microbiol Infect. 2012;18(10):1020-5.

16. Li J, O'Reilly N, Sheha H, Katz R, Raju VK, Kavanagh K, et al. Correlation between ocular Demodex infestation and serum immunoreactivity to Bacillus proteins in patients with Facial rosacea. Ophthalmology. 2010;117(5 e1):870-7.

17. O'Reilly N, Menezes N, Kavanagh K. Positive correlation between serum immunoreactivity to Demodex-associated Bacillus proteins and erythematotelangiectatic rosacea. Br J Dermatol. 2012;167(5):1032-6.

18. Lacey N, Delaney S, Kavanagh K, Powell FC. Mite-related bacterial antigens stimulate inflammatory cells in rosacea. Br J Dermatol. 2007;157(3):474-81.

19. Kirn T. Intense pulsed light eradicates Demodex mites. Skin Allergy News. 2002;33(1):37.

20. Prieto VG, Sadick NS, Lloreta J, Nicholson J, Shea CR. Effects of intense pulsed light on sun-damaged human skin, routine, and ultrastructural analysis. Lasers Surg Med. 2002;30(2):82-5.

21. Fishman HA, Periman LM, Shah AA. Real-Time Video Microscopy of In Vitro Demodex Death by Intense Pulsed Light. Photobiomodul Photomed Laser Surg. 2020.

22. Cheng S-n, Jiang F-g, Chen $\mathrm{H}$, Gao $\mathrm{H}$, Huang Y-k. Intense Pulsed Light Therapy for Patients with Meibomian Gland Dysfunction and Ocular Demodex Infestation. Curr Med Sci. 2019;39(5):800-9.

23. Karu TI, Kolyakov SF. Exact action spectra for cellular responses relevant to phototherapy. Photomed Laser Surg. 2005;23(4):355-61.

24. Karu T. Primary and secondary mechanisms of action of visible to near-IR radiation on cells. J Photoch Photobio B. 1999;49(1):1-17.

25. Takezaki S, Omi T, Sato S, Kawana S. Ultrastructural observations of human skin following irradiation with visible red light-emitting diodes (LEDs): A preliminary in vivo report. Laser Ther. 2005;14(4):153-9.

26. Takezaki S, Omi T, Sato S, Kawana S. Light-emitting diode phototherapy at $630+/-3 \mathrm{~nm}$ increases local levels of skin-homing T-cells in human subjects. J Nippon Med Sch. 2006;73(2):75-81.

27. Young S, Bolton P, Dyson M, Harvey W, Diamantopoulos C. Macrophage responsiveness to light therapy. Lasers Surg Med. 1989;9(5):497-505.

28. Cuerda-Galindo E, Diaz-Gil G, Palomar-Gallego MA, Linares-GarciaValdecasas R. Increased fibroblast proliferation and activity after applying intense pulsed light 800-1200 nm. Ann Anat. 2015;198:66-72.

29. Barolet D, Roberge CJ, Auger FA, Boucher A, Germain L. Regulation of skin collagen metabolism in vitro using a pulsed $660 \mathrm{~nm}$ LED light source: clinical correlation with a single-blinded study. J Invest Dermatol. 2009;129(12):2751-9.

30. Bäumler W, Vural E, Landthaler M, Muzzi F, Shafirstein G. The effects of intense pulsed light (IPL) on blood vessels investigated by mathematical modeling. Laser Surg Med. 2007;39(2):132-9.

31. Dell SJ. Intense pulsed light for evaporative dry eye disease. Clin Ophthalmol. 2017;11:1167.

32. Wu Y, Li J, Hu M, Zhao Y, Lin X, Chen Y, et al. Comparison of two intense pulsed light patterns for treating patients with meibomian gland dysfunction. Int Ophthalmol. 2020.

33. Yagci A, Gurdal C. The role and treatment of inflammation in dry eye disease. Int Ophthalmol. 2014;34(6):1291-301.

34. Augustin AJ, Spitznas M, Kaviani N, Meller D, Koch FH, Grus F, et al. Oxidative reactions in the tear fluid of patients suffering from dry eyes. Graefes Arch Clin Exp Ophthalmol. 1995;233(11):694-8.

35. Knop E, Knop N, Millar T, Obata H, Sullivan DA. The international workshop on meibomian gland dysfunction: report of the subcommittee on anatomy, physiology, and pathophysiology of the meibomian gland. Invest Ophthalmol Vis Sci. 2011;52(4):1938-78.

36. Liu Y, Chen D, Chen X, Kam WR, Hatton MP, Sullivan DA. Hypoxia: A breath of fresh air for the meibomian gland. Ocul Surf. 2019;17(2):310-7. 
37. Craig JP, Chen YH, Turnbull PR. Prospective trial of intense pulsed light for the treatment of meibomian gland dysfunction. Invest Ophthalmol Vis Sci. 2015;56(3):1965-70.

38. Moniaux N, Escande F, Porchet N, Aubert J-P, Batra SK. Structural organization and classification of the human mucin genes. Front Biosci. 2001;6(1):D1192-D206.

39. Gipson IK, Hori Y, Argüeso P. Character of ocular surface mucins and their alteration in dry eye disease. Ocul Surf. 2004;2(2):131-48.

40. Gipson IK, Argueso P. Role of mucins in the function of the corneal and conjunctival epithelia. Int Rev Cytol. 2003;231(1):1-49.

41. Xue AL, Wang MTM, Ormonde SE, Craig JP. Randomised double-masked placebo-controlled trial of the cumulative treatment efficacy profile of intense pulsed light therapy for meibomian gland dysfunction. Ocul Surf. 2020.

42. Cote S, Zhang AC, Ahmadzai V, Maleken A, Li C, Oppedisano J, et al. Downie LE.Intense Pulsed Light (IPL) Therapy for the Treatment of Meibomian Gland Dysfunction. Cochrane Database Syst Rev. 2020;3(3):CD013559.

43. Arita R, Fukuoka S, Morishige N. Therapeutic efficacy of intense pulsed light in patients with refractory meibomian gland dysfunction. Ocul Surf. 2019;17(1):104-10.

44. Arita R, Mizoguchi T, Fukuoka S, Morishige N. Multicenter Study of Intense Pulsed Light Therapy for Patients With Refractory Meibomian Gland Dysfunction. Cornea. 2018;37(12):1566-71.

45. Yurttaser Ocak S, Karakus S, Ocak OB. Intense pulse light therapy treatment for refractory dry eye disease due to meibomian gland dysfunction. Int Ophthalmol. 2020; 40(5):1135-41.

46. Giannaccare G, Taroni L. Intense Pulsed Light Therapy In The Treatment Of Meibomian Gland Dysfunction: Current Perspectives. Clin Optom (Auckl). 2019;11:113-26.

47. Guilloto Caballero S, García Madrona JL, Colmenero Reina E. Effect of pulsed laser light in patients with dry eye syndrome. Arch Soc Esp Oftalmol. 2017;92(11):509-15.

48. Vigo L, Giannaccare G, Sebastiani S, Pellegrini M, Carones F. Intense Pulsed Light for the Treatment of Dry Eye Owing to Meibomian Gland Dysfunction. J Vis Exp. 2019(146)

49. Vigo L, Taroni L, Bernabei F, Pellegrini M, Sebastiani S, Mercanti A, et al. Ocular Surface Workup in Patients with Meibomian Gland Dysfunction Treated with Intense Regulated Pulsed Light. Diagnostics (Basel).2019;9(4):147.

50. Dell SJ, Gaster RN, Barbarino SC, Cunningham DN. Prospective evaluation of intense pulsed light and meibomian gland expression efficacy on relieving signs and symptoms of dry eye disease due to meibomian gland dysfunction. Clin Ophthalmol. 2017;11:817-27.

51. Lam PY, Shih KC, Fong PY, Chan TCY, Ng AL, Jhanji V, et al. A Review on Evidence-Based Treatments for Meibomian Gland Dysfunction. J Cosmet Dermatol. 2020;46(1):3-16.

52. Vora GK, Gupta PK. Intense pulsed light therapy for the treatment of evaporative dry eye disease. Curr Opin Ophthalmol. 2015;26(4):314-8.

53. Rennick S, Adcock L. Intense Pulsed Light Therapy for Meibomian Gland Dysfunction: A Review of Clinical Effectiveness and Guidelines. Ottawa (ON): Canadian Agency for Drugs and Technologies in Health. 2018

54. Schuh A, Priglinger S, Messmer EM. [Intense pulsed light (IPL) as a therapeutic option for Meibomian gland dysfunction]. Ophthalmologe. 2019;116(10):982-8

55. Cote S, Zhang AC, Ahmadzai V, Maleken A, Li C, Oppedisano J, et al. Intense pulsed light (IPL) therapy for the treatment of meibomian gland dysfunction. J Ophthalmic Vis Res. 2020;3(3):Cd013559.

56. Choi M, Han SJ, Ji YW, Choi YJ, Jun I, Alotaibi MH, et al. Meibum Expressibility Improvement as a Therapeutic Target of Intense Pulsed Light Treatment in Meibomian Gland Dysfunction and Its Association with Tear Inflammatory Cytokines. Sci Rep. 2019;9(1):7648.

57. Rong B, Tang Y, Liu R, Tu P, Qiao J, Song W, et al. Long-Term Effects of Intense Pulsed Light Combined with Meibomian Gland Expression in the Treatment of Meibomian Gland Dysfunction. Photomed Laser Surg. 2018;36(10):562-7.

58. Ruan F, Zang Y, Sella R, Lu H, Li S, Yang K, et al. Intense Pulsed Light Therapy with Optimal Pulse Technology as an Adjunct Therapy for Moderate to Severe Blepharitis-Associated Keratoconjunctivitis. J Ophthalmol. 2019;2019:3143469.

59. Rong B, Tang Y, Tu P, Liu R, Qiao J, Song W, et al. Intense Pulsed Light Applied Directly on Eyelids Combined with Meibomian Gland Expression to Treat Meibomian Gland Dysfunction. Photomed Laser Surg. 2018;36(6):326-32.

60. Huang X, Oin Q, Wang L, Zheng J, Lin L, Jin X. Clinical results of Intraductal Meibomian gland probing combined with intense pulsed light in treating patients with refractory obstructive Meibomian gland dysfunction: a randomized controlled trial. BMC Ophthalmol. 2019;19(1):211.

61. Gupta PK, Vora GK, Matossian C, Kim M, Stinnett S. Outcomes of intense pulsed light therapy for treatment of evaporative dry eye disease. Can J Ophthalmol. 2016;51(4):249-53.

62. Piyacomn $\mathrm{Y}$, Kasetsuwan $\mathrm{N}$, Reinprayoon $\mathrm{U}$, Satitpitakul V, Tesapirat L. Efficacy and Safety of Intense Pulsed Light in Patients With Meibomian Gland Dysfunction-A Randomized, Double-Masked, Sham-Controlled Clinical Trial. Cornea. 2020;39(3):325-332.

63. Li D, Lin SB, Cheng B. Intense Pulsed Light Treatment for Meibomian Gland Dysfunction in Skin Types III/IV. Photobiomodul Photomed Laser Surg. 2019;37(2):70-6.
64. Khan $\mathrm{MH}$, Sink $\mathrm{RK}$, Manstein $\mathrm{D}$, Eimerl $\mathrm{D}$, Anderson RR. Intradermally focused infrared laser pulses: thermal effects at defined tissue depths. Lasers Surg Med. 2005;36(4):270-80.

65. Thomas MM, Houreld NN. The "in's and outs" of laser hair removal: a mini review. J Cosmet Laser Ther. 2019;21(6):316-22.

66. Ahmed SA, Taher IME, Ghoneim DF, Safwat AEM. Effect of Intense Pulsed Light Therapy on Tear Proteins and Lipids in Meibomian Gland Dysfunction. J Ophthalmic Vis Res. 2019;14(1):3-10.

67. Liu R, Rong B, Tu P, Tang Y, Song W, Toyos R, et al. Analysis of Cytokine Levels in Tears and Clinical Correlations After Intense Pulsed Light Treating Meibomian Gland Dysfunction. Am J Ophthalmol. 2017;183:81-90.

68. Karaca EE, Evren Kemer O, Ozek D. Intense regulated pulse light for the meibomian gland dysfunction. Eur J Ophthalmol. 2020 Mar;30(2):289-292

69. Seo KY, Kang SM, Ha DY, Chin HS, Jung JW. Long-term effects of intense pulsed light treatment on the ocular surface in patients with rosacea-associated meibomian gland dysfunction. Cont Lens Anterior Eye. 2018;41(5):430-5

70. Gao YF, Liu RJ, Li YX, Huang C, Liu YY, Hu CX, et al. Comparison of anti-inflammatory effects of intense pulsed light with tobramycin/dexamethasone plus warm compress on dry eye associated meibomian gland dysfunction. Int J Ophthalmol. 2019;12(11):1708-13.

71. Godin MR, Stinnett SS, Gupta PK. Outcomes of Thermal Pulsation Treatment for Dry Eye Syndrome in Patients With Sjogren Disease. Cornea. 2018;37(9):1155-8.

72. Yin Y, Liu N, Gong L, Song N. Changes in the Meibomian Gland After Exposure to Intense Pulsed Light in Meibomian Gland Dysfunction (MGD) Patients. Curr Eye Res. 2018;43(3):308-13.

73. Chhadva P, Goldhardt R, Galor A. Meibomian Gland Disease: The Role of Gland Dysfunction in Dry Eye Disease. Ophthalmology. 2017;124(11S):S20-S6.

74. Rong B, Tu P, Tang Y, Liu RX, Song WJ, Yan XM. [Evaluation of short-term effect of intense pulsed light combined with meibomian gland expression in the treatment of meibomian gland dysfunction]. Zhonghua Yan Ke Za Zhi. 2017;53(9):675-81.

75. Jiang X, Lv H, Song H, Zhang M, Liu Y, Hu X, et al. Evaluation of the Safety and Effectiveness of Intense Pulsed Light in the Treatment of Meibomian Gland Dysfunction. J Ophthalmol. 2016;2016:1910694

76. Choi M, Han SJ, Ji YW. Meibum Expressibility Improvement as a Therapeutic Target of Intense Pulsed Light Treatment in Meibomian Gland Dysfunction and Its Association with Tear Inflammatory Cytokines. Sci Rep. 2019;9(1):7648. 